\title{
Торф - неиспользованный сырьевой ресурс северо-запада Российской Арктики
}

\section{Евзеров В.Я.}

Геологический институт КНЦ РАН, Аnатить

Аннотация. Приведены краткие сведения о месторождениях торфа северо-запада Российской Арктики (Кольского региона). Предложена эксплуатация торфяных залежей для производства гуматов без осушения болот. Осушение болот неизбежно имело бы отрицательные экологические последствия.

Ключевые слова: месторождения торфа, перспективы освоения.

\section{Peat - as an untapped resource of the North-Western Russian Arctic}

\section{Yevzerov V.Ya.}

Geological Institute Kola SC RAS, Apatity

Abstract. Brief data on peat deposits of the North-Western Russian Arctic are provided. The article suggests ways of utilizing peat deposits to produce humates with no dry-out of mires that would inevitably affect the ecology.

Key words: deposits, peat, development perspectives.

\section{Введение}

Многие полезные ископаемые северо-запада Российской Арктики (Кольского региона), приуроченные к кристаллическим породам, достаточно активно эксплуатируются. Из рыхлого покрова берутся практически только стройматериалы, такие как пески и песчано-гравийные смеси. Производство глиняного кирпича прекратилось. Ведётся нерегулярная добыча торфа для нужд сельского хозяйства. Однако сырьевые ресурсы четвертичных отложений, как мы покажем далее относительно месторождений торфа, могут использоваться гораздо эффективнее.

Органогенные полезные ископаемые широко распространены в северо-восточной части Балтийского щита. Это, прежде всего, торфяники и сапропели, представляющие значительный интерес для развития и промышленности и сельского хозяйства. В настоящее время они практически не используются. На существенно более ограниченных площадях встречается ракуша, которая может применяться при откорме птиц. Все органогенные ископаемые относятся к категории восстанавливающихся ресурсов. Они образовались в голоцене и существенным образом зависят от изменений климата. Поэтому целесообразно вкратце рассмотреть климатическую обстановку этого периода.

\section{Климат голоцена}

Климат региона в голоцене реконструировался различными методами. Его количественные характеристики восстанавливались по результатам изучения остатков хирономид, пыльцы и спор наземных растений (Елина и др., 1995; Ильяшук и др, 2007), а качественная оценка была впервые получена по материалам исследования прибрежно-морских образований (Møller et al., 2002). Мы сконцентрируем внимание на рассмотрении результатов, полученных на палеонтологической основе и приведенных на рисунке 1. Анализ графиков показывает, что климат многократно изменялся: чередовались потепления и похолодание. Значительно больше изменений зафиксировано по палинологии, чем по материалам изучения хирономид. Судя по графикам (рис. 1 Б), наиболее значительное потепление имело место в атлантический период, несколько меньшее по амплитуде - в суббореале. Повышениям температур, как правило, сопутствовало и увеличение количества осадков.

\section{торфяные месторождения}

Согласно Геологическому словарю (Геологический..., 1978) торф является горючим полезным ископаемым, относящимся к гумитам. Он представляет собой первую стадию превращения растительного материала по пути его преобразования в уголь. Торф накапливается в болотах из 
A

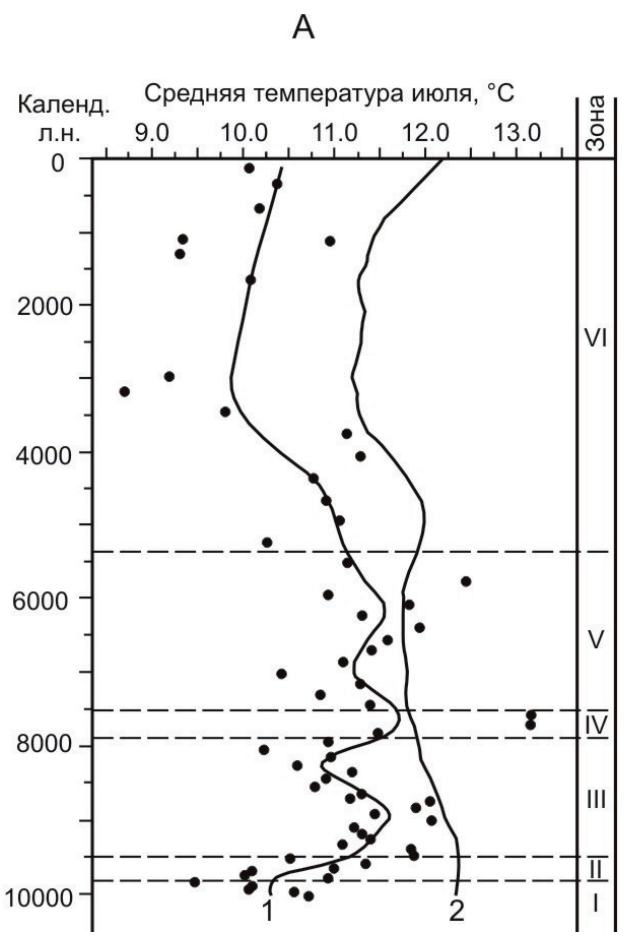

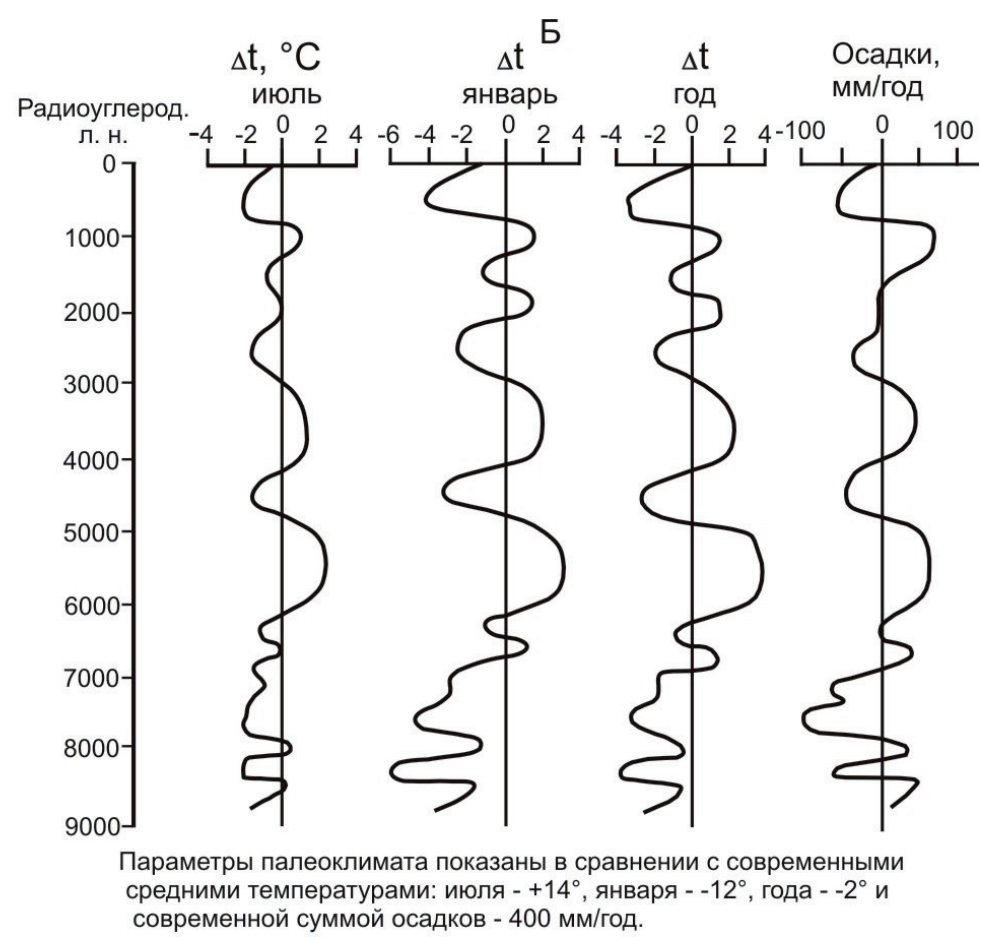

Рис. 1. Реконструкции климатических показателей голоцена по материалам изучения хирономид (А) и спорово-пыльцевых спектров (Б) (Елина и др., 1995; Ильяшук и др, 2007). А: 1 - озеро Купальное в предгорьях Хибин, 2 - оз. Беркут на Беломорском побережье Кольского полуострова. Б: бугристое топяное болото севернее Ловозерских тундр (68 6 с. ш. и $35^{\circ}$ в. д.).

Fug. 1. Reconstructions of climatic characteristics in the Holocene based on the study of chironomides (A) and pollenspore spectra (B) [1, 2]: (A) 1 - Kupalnoye Lake at the Khibiny foothills, 2 - Berkut Lake at the White Sea coast of the Kola Peninsula; (B) hummocky bog to the north of the Lovozero tundra ( $68^{\circ}$ n.l. and $35^{\circ}$ e.1.).

остатков отмерших растений, которые подвергаются неполному разложению в условиях повышенной влажности и затрудненного доступа воздуха. Главную роль при торфообразовании играют процессы биохимической гумификации, протекающие при участии микроорганизмов. В результате образуется гумус, процентное содержание которого определяет степень разложения торфа, влияющую наряду с флористическим составом на все его важнейшие свойства. Структура торфа волокнообразная при низкой (до 25 \%) и аморфная при высокой (50-65 \%) степени разложения. Его влажность составляет 75-95\%. Содержание минеральных примесей в низинных торфах (грунтовое питание) варьирует от 4 до $18 \%$, а в верховых (атмосферное питание) - от 2 до $4 \%$. Пористость торфа малой степени разложения очень велика (70-80 \%), тогда как сильно разложившегося торфа обычно незначительна. Органическая масса торфа содержит примерно 52-62 \% углерода, 4.5-6.5 \% водорода, 1-2.9 \% азота, 31-42 \% кислорода и 0.1-1.5 \% серы. Кроме того, в нем присутствуют сахара.

В мире добывается порядка 20 млн. т торфа, 12 из них в Финляндии и примерно 2 в России (Вешняковская, 2011). Торф является ценным экологически чистым биотопливом в связи с высоким содержанием углерода и низкими содержаниями серы и других вредных негорючих остатков и примесей. Основным недостатком торфа является более низкая калорийность, чем угля, и высокое содержание влаги (до 65 \%), затрудняющей его сжигание. В структуре топливных ресурсов России торф занимает второе место после угля (43 \%). На его долю в пересчете на тонны условного топлива приходится 29 \%, тогда как его использование не превышает 0.05 \% (Вешняковская, 2011). Торф в качестве топлива активно употребляется в таких странах, как Финляндия и Канада.

Торф обладает рядом качеств, делающих его весьма полезным для земледелия. Он богат гумусом, являющимся основой плодородия почвы. Для перевода гумуса, содержащегося в торфе в связанном состоянии, в воднорастворимые гуматы торф необходимо подвергнуть обработке тем или иным способом. Гуматы - не только питание, но и прекрасные стимуляторы роста. Они могут быть исполь- 
зованы также для санации территорий в районах хранения и уничтожения химического оружия, обеззараживания земли от некоторых радионуклеидов и очистки сточных вод от тяжелых металлов. Кроме того, гумус может связывать деградированные почвы, которые выдуваются ветром или размываются водой. Торф является хорошим влагорегулятором, обладает бактерицидными свойствами и способностью к поглощению большого количества газов. В старину верховой сфагновый торф, имеющий пористую структуру, использовался как перевязочное средство. В чистом виде торф применяется для улучшения структуры обрабатываемой почвы, для аккумуляции и длительного удержания влаги в почве, а также для создания среды, способствующей увеличению кислородообменных процессов. В настоящее время, применяя торф как основу, готовят субстрат для растений, культивируемых в теплицах, органические удобрения, подстилки для скота и блоки для выращивания рассады. В Мурманской области торфяники после мелиорирования используются в качестве сельскохозяйственных угодий. При глубокой переработке торфа под действием высоких температур из него получают активный уголь, который применяется в медицине, биохимии и промышленности в качестве абсорбентов, фильтрующих элементов, газопоглотителей и восстановителей металлов.

На крайнем северо-западе России широко распространены залежи торфа. Они приурочены, в основном, к болотам, сформировавшимся в голоцене. Заболоченность Мурманской области по данным из разных источников составляет от 26 до 37 \% (Атлас..., 1968; Новиков, Усова, 2000). В тундровой зоне на долю болот приходится всего 10-20\%, тогда как в таёжной зоне - от 20-70 \% (Елина и др.. 2005). Типизация болот и их распространение на территории Мурманской области показаны на рисунке 2.

Анализ схемы свидетельствует, что наиболее широко развиты аапа болота, в которых низинный торф по периферии окаймлён торфом верховым. Реже встречаются бугристые болота, еще реже

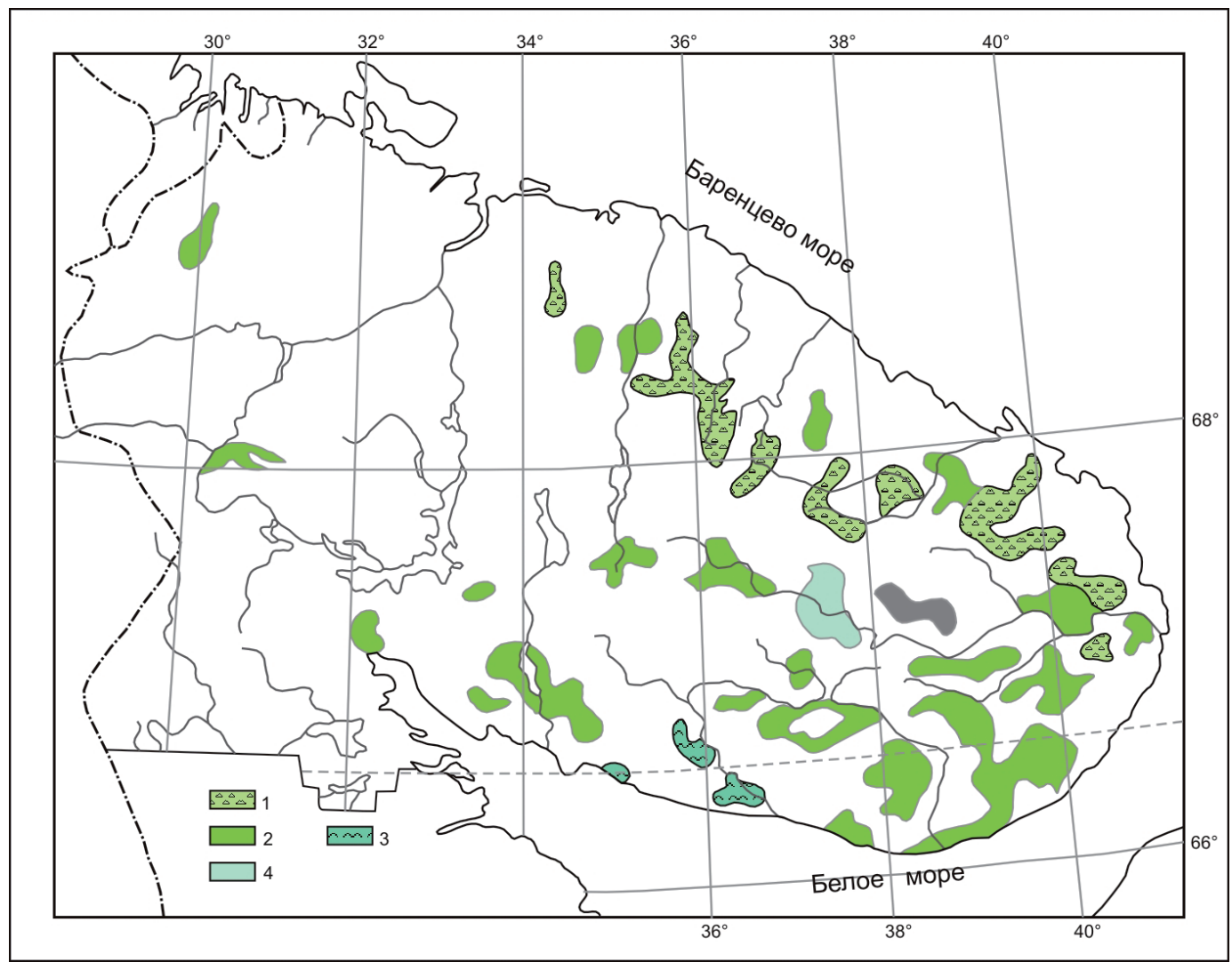

Рис. 2. Схема распространения болотных массивов Мурманской области (приводится по: (Елина и др., 2000) с упрощением и дополнением). 1 - бугристые болота; 2 - аапа болота; 3 - верховые сфагновые болота; 4 - низинные травяные болота.

Fig. 2. The scheme of distribution of bog areas in the Murmansk region (after [9], simplified and added). 1 - hummocky bogs; 2 - aapa mires; 3 - upland sphagnum moors; 4 - lowland meadow bogs. 
верховые сфагновые и крайне редко - низинные травяные болота. Бугристые болота локализованы в тундре и лесотундре. Их рельеф обязан своим происхождением мерзлотным процессам.

В распределении болот по площади наряду с климатическими особенностями существенную роль, несомненно, играет рельеф. На приведенном рисунке хорошо видно, что болота сконцентрированы в восточной части Мурманской области, которая отличается от западной более спокойным и низким, слабо пересеченным рельефом.

По материалам Комитета промышленного развития Мурманской области, материалов ЗАО «Русская торфяная земля» и торфяного фонда РСФСР, балансом по области учитывается 48 месторождений торфа площадью более 10 га с общей площадью 9918,62 га и запасами 13376 тыс. т торфа. Запасы торфа по 13 месторождениям площадью от 1 до 10 га составляют 178 тыс. т. Перспективы добычи торфа на территории области обусловлены наличием 620 месторождений общей площадью 379575 га с прогнозными ресурсами 853403 тыс. т торфа. Всего же при проведении поисково-разведочных работ были оценены запасы 815 месторождений с площадью в границах промышленной залежи 388.18 тыс. га и запасами торфа 907.5 млн. т при $40 \%$ влажности.

Наиболее распространены месторождения площадью до 100 га. По количеству они составляют $80 \%$, а по запасам на их долю приходится всего $4.4 \%$. Основные запасы торфа (87 \%) сосредоточены в 26 месторождениях, площадь каждого из которых превышает 1000 га. Самые крупные месторождения сосредоточены в верховьях рек Поной, Варзуга и их притоков. Залежи всех типов торфа в Мурманской области маломощные: их средняя толщина варьирует от 0.99 до 1.52 м. Уместно отметить, что в районе городов Апатиты и Кировска, а также села Ловозеро среди большого количества мелких месторождений встречаются и крупные площадью в несколько тысяч га, которые могут активно эксплуатироваться.

В Мурманской области, как отмечалось, ведется нерегулярная добыча торфа для нужд сельского хозяйства. Очевидно, что в качестве горючего полезного ископаемого торф не может конкурировать с относительно дешёвым мазутом. Однако гуматы могут и должны найти практическое применение. В настоящее время они широко используются, в частности, для борьбы с опустыниванием местностей. Белоруссия, например, успешно продаёт гуматы в Арабские эмираты. Ей уже не хватает сырьевой базы торфяников, чтобы удовлетворить спрос (Вешняковская, 2011). Проблема опустынивания актуальна во всех засушливых регионах Земли.

Там, где крупные месторождения торфа имеются вблизи населенных пунктов, целесообразно наладить добычу торфа для производства гуматов, имея в виду не только использование их внутри страны, но и широкие возможности экспорта. Несомненно, потребуется предварительная экономическая проработка вопроса. Кроме того, будет целесообразным и детальное изучение торфяных залежей, намеченных к освоению, чтобы выбрать среди них залежь с максимальной скоростью нарастания торфа, поскольку торфяники относятся к числу естественно возобновляемых ресурсов. Не следует проводить осушение болот, что ведет к весьма неблагоприятным экологическим последствиям. Очевидно, необходимо отрабатывать торфяные залежи полосами, оставляя между ними достаточно широкие нетронутые целики. Это позволит сохранить болото как элемент ландшафта, и через некоторое время использовать для переработки растительные остатки, накопившиеся в отработанных полосах. Создание новых производств будет способствовать повышению жизнестойкости городов, возникших в связи с деятельностью одного крупного градообразующего предприятия. Такими городами в Мурманской области являются Апатиты, Кировск, Мончегорск и др.

Скорость нарастания торфа зависит от климата и, несомненно, изменялась на протяжении голоцена. Однако имеющихся материалов недостаточно для корректного определения изменения скорости накопления торфа во времени. Средние скорости нарастания торфа рассчитаны нами по данным (Елина и др., 2000). Они составили в тундре $0.2-0.3$ мм/год, в лесотундре - от 0.15 до 0.4 мм/год и в тайге - от 0.1 до 0.76 мм/год. Г.А. Елина с соавторами (Елина и др., 2000) указывают, что в болоте Ловозерское у села Ловозеро скорость накопления торфа в субатлантический период была выше, чем в суббореальный и атлантический периоды ( 0.08 мм/год), и составляла 0.25 мм/год. 


\section{Заключение}

Обилие месторождений торфа в регионе позволяет организовать его добычу для производства, главным образом, гуматов. Гуматы являются стимуляторами роста растений и могут быть использованы также для санации территорий в районах хранения и уничтожения химического оружия, обеззараживания земли от некоторых радионуклеидов и очистки сточных вод от тяжелых металлов. Кроме того, гумус способствует сохранению деградирующих почв, выдуваемых ветром или размываемых водой. Гуматы найдут применение не только в России, но и за рубежом. Торфяные залежи необходимо отрабатывать полосами, оставляя между ними достаточно широкие нетронутые целики. Это позволит сохранить болото как элемент ландшафта, избежать негативных экологических последствий, неизбежных при осушении болот, и через некоторое время использовать для переработки растительные остатки, накопившиеся в отработанных полосах.

\section{Литература}

1. Атлас торфяных ресурсов СССР. М. Изд-во: ГУГиХ. 1968. 96 с.

2. Вешняковская Е. Торф как национальная идея // Наука и жизнь. 2011. № 4. С. 44-55.

3. Геологический словарь. Т. 2. М. Изд-во: Недра. 1978. С. 320-321.

4. Елина Г.А., Арсланов Х.А., Климанов В.А.. Усова Л.И. Растительность и климатохронология голоцена Ловозерской равнины Кольского полуострова (по спорово-пыльцевым диаграммам бугристо топяного болота) // Ботанический журнал. Т. 80. № 3. 1995. С. 1-16.

5. Елина Г.А., Лукашов А.Д., Юрковская Т.К. Позднеледниковье и голоцен восточной Фенноскандии (палеорастительность и палеогеография) // Петрозаводск. Изд-во: КарНЦ РАН. 2000. 242 с.

6. Елина Г.А., Филимонова Л.В., Грабовик С.И., Костина В.И. Болота Кольского полуострова // Труды КарНЦ РАН. Вып. 8. 2005. С. 94-111.

7. Ильяшук Б.П., Ильяшук Е.А., Хаммарлунд Д. Изменения климата в предгорьях Хибин, Кольский полуостров, на протяжении голоцена // Бюл. ком. по изуч. четвертич. периода. 2007. № 67. С. 85-96.

8. Новиков С.М., Усова Л.И. Новые данные о площади болот и запасах торфа на территории России // Материалы междун. симпозиума «Динамика болотных экосистем северной Евразии в голоцене» (Петрозаводск, 5-9 октября 1998 г.). Петрозаводск. Изд-во: КарНЦ РАН. 2000. С. 49-52.

9. Møller J.J., Yevzerov V.Y., Kolka V.V., Corner G.D. Holocene raised-beach ridges and sea-ice-pushed boulders on the Kola Peninsula: indicators of climatic change // The Holocene. V. 12. № 2. 2002. P. 169-176. 